\title{
Estimating the potential impact of the Australian government's reformulation targets on household sugar purchases
}

\author{
Daisy H. Coyle ${ }^{1 *} \mathbb{D}$, Maria Shahid ', Elizabeth K. Dunford ${ }^{1,2}$, Jimmy Chun Yu Louie ${ }^{1,3}$, Kathy Trieu', \\ Matti Marklund ${ }^{1,4}$, Bruce Neal ${ }^{1}$ and Jason H. Y. Wu ${ }^{1}$
}

\begin{abstract}
Background: Countries around the world are putting in place sugar reformulation targets for packaged foods to reduce excess sugar consumption. The Australian government released its voluntary sugar reformulation targets for nine food categories in 2020. We estimated the potential impact of these targets on household sugar purchases and examined differences by income. For comparison, we also modelled the potential impact of the UK sugar reduction targets on per capita sugar purchases as the UK has one of the most comprehensive sugar reduction strategies in the world.
\end{abstract}

Methods: Grocery purchase data from a nationally representative consumer panel $(n=7,188)$ in Australia was linked with a large database (FoodSwitch) with product-specific sugar content information for packaged foods $(n=25,261)$; both datasets were collected in 2018. Potential reductions in per capita sugar purchases were calculated overall and by food category. Differences in sugar reduction across income level were assessed by analysis of variance.

Results: In 2018, the total sugar acquired from packaged food and beverage purchases consumed at-home was 56.1 $\mathrm{g} /$ day per capita. Australia's voluntary reformulation targets for sugar covered 2,471/25,261 (9.8\%) unique products in the FoodSwitch dataset. Under the scenario that all food companies adhered to the voluntary targets, sugar purchases were estimated to be reduced by $0.9 \mathrm{~g} /$ day per capita, which represents a $1.5 \%$ reduction in sugar purchased from packaged foods. However, if Australia adopted the UK targets, over twice as many products would be covered $(n=4,667)$, and this would result in a more than four times greater reduction in sugar purchases (4.1 g/day per capita). It was also estimated that if all food companies complied with Australia's voluntary sugar targets, reductions to sugar would be slightly greater in low-income households compared with high-income households by $0.3 \mathrm{~g} /$ day $(95 \% \mathrm{Cl} 0.2$ - $0.4 \mathrm{~g} /$ day, $p<0.001$ ).

Conclusions: Sugar-reduction policies have the potential to substantially reduce population sugar consumption and may help to reduce health inequalities related to excess sugar consumption. However, the current reformulation targets in Australia are estimated to achieve only a small reduction to sugar intakes, particularly in comparison to the UK's sugar reduction program.

*Correspondence: dcoyle@georgeinstitute.org.au

${ }^{1}$ Faculty of Medicine, The George Institute for Global Health, UNSW Sydney, Level 5, 1 King St, Newtown, Australia

Full list of author information is available at the end of the article

\section{Introduction}

Excess sugar intake is associated with adverse health outcomes including unhealthy weight gain $[1,2]$, dental caries [3] and type 2 diabetes [4, 5]. The World Health Organization (WHO) recognizes the importance of reducing population sugar consumption and original author(s) and the source, provide a link to the Creative Commons licence, and indicate if changes were made. The images or other third party material in this article are included in the article's Creative Commons licence, unless indicated otherwise in a credit line to the material. If material is not included in the article's Creative Commons licence and your intended use is not permitted by statutory regulation or exceeds the permitted use, you will need to obtain permission directly from the copyright holder. To view a copy of this licence, visit http://creativecommons.org/licenses/by/4.0/. The Creative Commons Public Domain Dedication waiver (http://creativeco mmons.org/publicdomain/zero/1.0/) applies to the data made available in this article, unless otherwise stated in a credit line to the data. 
recommends that adults and children reduce their daily intake of 'free' sugar (which includes added sugars as well as naturally occurring sugars in honey, syrup and fruit juice) to less than $10 \%$ of total energy [6]. In Australia, approximately half of the adult population ( $47 \%$ of men and $44 \%$ of women) exceeds this recommendation [7]. Intakes of free sugar are particularly high in young adults (56\% and $59 \%$ of men and women aged 18 - 30 years consume $\geq 10 \%$ energy from free sugar, respectively) and in individuals with a low socioeconomic (SES) status $(\sim 50 \%$ exceed the recommended level of intake) [7].

Sugars added to processed foods is a major dietary source of free sugars globally [8-10]. In an attempt to achieve population-wide reductions in free sugar intake, a growing number of governments have adopted policies to reduce the amount of sugar added to processed foods $[11,12]$. For instance, the UK has one of the most comprehensive sugar reduction strategies in the world, which aims to reduce the amount of total sugar in targeted food and beverage products by $20 \%$ through a multicomponent approach that includes reformulation targets and portion size guidelines [12]. Policies targeting the reduction of sugar in the food system have tremendous potential to improve population health - for example, a modelling study has shown that if the UK sugar reduction program was achieved in its entirety, it could reduce sugar consumption in adults by $5 \%$, preventing up to 154,000 cases of diabetes over 10 years and generating an estimated $\sim 50,000$ quality adjusted life years [13].

In Australia, a large proportion of free sugars in the diet comes from energy-dense, nutrient-poor discretionary products, such as sugar-sweetened beverages and cakes $[8,14]$. To reduce population sugar intake, the Australian Federal government has released a series of voluntary reformulation targets as part of the Healthy Food Partnership initiative [15, 16]. The Healthy Food Partnership was established in 2015 and is a public-private partnership between government, the public health sector and the food industry that aims to improve the dietary habits of the Australian population [16]. The voluntary reformulation targets for total sugar were released in 2021 across nine packaged food and beverage categories [17].

The primary aim of this study was to estimate the potential impact of the Healthy Food Partnership sugar reformulation targets on the amount of sugar brought into the home from packaged food purchases. We examined the potential impact overall and for households with different income levels, since prior literature suggests lower socio-economic status groups consume higher intakes of sugar $[8,18-20]$. We also modelled reductions across food categories to estimate where the greatest sugar reductions are likely to be achieved. In addition, we modelled the amount of sugar reduction that could be achieved if Australia had adopted the UK targets, in order to gain insight into how the Australian targets compare against a more comprehensive sugar reduction program.

\section{Method}

This project was approved by the University of New South Wales Human Research Ethics Committee (approval number HC180965).

\section{Study design and population}

This study used data from the NielsenIQ Homescan Consumer Panel [21], a commercial dataset that contains information on food and beverage purchases made by Australian households. Data over a one-year period (January- December 2018) was used for the current analysis, which contained information from approximately 10,000 households who recorded all food and beverages purchased and brought into the home throughout the year. Participating households are recruited to ensure the panel is representative of the demographic composition and geographic location of Australian households [22]. The dataset contains information on the sociodemographic characteristics of the households, including ethnicity and education level of the main shopper in the household, household income, and age and sex of all household members. This dataset is frequently used by researchers to examine food and beverage purchasing habits as a proxy for consumption [22-25].

Participating households are provided with a handheld electronic scanner and are instructed to scan the barcodes of all packaged food and beverage items purchased from retail outlets including supermarkets and convenience stores. Data are not collected on foods and beverages purchased and consumed outside of the home, for example from restaurants and take-away outlets. To best capture usual shopping purchases made throughout the year and to account for products that are stored and not consumed immediately, we analyzed year-level purchases by summing all purchases made during the 2018 calendar year.

\section{Household exclusion criteria}

Using NielsenIQ quality standard criteria, we excluded households if they were not on the panel for the entire 52-week time frame, if they did not record any purchases (at least one barcode per week) for at least $50 \%$ of the weeks, if they were missing any demographic information or if they did not meet minimum spend criteria ( $\geq \$ 5$ on average for each week for all purchases). To further exclude households that may have under-reported purchases, households with the lowest annual food and beverage expenditure $\left(<2.5^{\text {th }}\right.$ percentile defined separately 
for single-member households and multi-member households) were also excluded [22].

\section{Food and beverage nutrient data}

Each barcoded product purchased by Homescan households was linked to its corresponding nutrition information panel (NIP) to obtain the total sugar content. Information from the NIP was obtained from the 2018 FoodSwitch annual database [26-28], which contains nutrition information for packaged food and beverage products available for sale from five large supermarket retailers in Australia (Woolworths, Coles, Aldi, IGA and Harris Farm) who together make up about $80 \%$ of the market share of packaged grocery products in Australia [29]. This information was collected by trained personnel during in-store collections in the months of August to November in 2018 (no crowd-sourced data was used in this study). Using the categorization system developed by the Global Food Monitoring Group, each food and beverage product in the FoodSwitch database was classified into a hierarchical category tree to allow for comparison of nutritionally similar foods [22, 27, 30, 31]. This classifies products into food groups (e.g. non-alcoholic beverages), categories (e.g. fruit and vegetable juices), subcategories (e.g. fruit juice) and leaf categories (e.g. apple juice).

A total of 22,738 products were directly linked to their nutritional information via their unique barcodes, which accounted for $85 \%$ of the quantity of product units purchased by the households. To further improve the coverage of products purchased by households, we applied additional matching steps using previously described methods [22, 32]. This included linking products by their (i) product name and (ii) product name after removing nutritionally irrelevant descriptors such as size and shape information. After applying these additional matching steps, the number of matched products increased to 25,261 , representing $88 \%$ of the total quantity of products purchased by households in 2018 .

\section{Modelled scenarios}

\section{Australian government's sugar reformulation targets}

Australia's sugar reformulation targets contain both maximum and proportional sugar targets across nine food and beverage categories. The food categories (and their target levels) include: breakfast cereals with fruit $(22.5 \mathrm{~g} / 100 \mathrm{~g}$ and at least a $20 \%$ reduction for products containing more than $28 \mathrm{~g}$ sugar/100 g); breakfast cereals without fruit $(20 \mathrm{~g} / 100 \mathrm{~g}$ and at least a $20 \%$ reduction for products containing more than $25 \mathrm{~g}$ sugar/100 $\mathrm{g})$; flavoured milk - mammalian $(9 \mathrm{~g} / 100 \mathrm{~mL})$; flavoured milk - dairy alternatives $(5 \mathrm{~g} / 100 \mathrm{~mL})$; muesli and snack bars $(25 \mathrm{~g} / 100 \mathrm{~g}$ and at least a $15 \%$ reduction for products containing more than $28.5 \mathrm{~g}$ sugar/100 g), flavoured water $(5 \mathrm{~g} / 100 \mathrm{~mL})$, flavoured mineral water, soda water and iced tea, carbonated soft drinks and energy drinks (a 10\% reduction for products containing more than $10 \mathrm{~g}$ sugar/100 mL), fruit drinks $(9.5 \mathrm{~g} / 100 \mathrm{~mL})$ and sweetened yoghurt (mammalian) (12.5 g/100 g). Further details about each of the targeted food categories is provided in Supplementary Table 1.

The first step in our modelling analyses was to map the nine categories to the FoodSwitch dataset to identify which foods and beverages fall under each of these targeted food categories. Using the Australian government's Healthy Food Partnership reformulation food category definitions [17], a researcher within the study team manually linked each of the targeted food categories to the relevant leaf categories (the finest category level) in FoodSwitch. For example, a number of leaf categories were mapped to the 'Fruit Drink' sugar target including 'apple juice,' 'apple-mango juice' and 'pineapple juice.' Targets were linked to leaf categories to reduce the risk of irrelevant products being mapped to the targets.

We modelled the potential reductions to Australian household sugar purchases by comparing the current amount of sugar purchased from packaged foods and beverages to a 'best-case' scenario whereby all products were successfully reformulated to meet the targets [17]. For food categories with a maximum target, foods and beverages with a sugar content at or below the target level were assumed to retain their existing sugar content, whereas, foods and beverages with a sugar content above the target level were hypothetically reformulated so that the sugar content was equal to the category-specific sugar target. For example, in the sweetened yoghurt category where the target is $12.5 \mathrm{~g} / 100 \mathrm{~g}$, if a sweetened yoghurt had a sugar level of $10 \mathrm{~g} / 100 \mathrm{~g}$, then we assumed its sugar content would remain the same. Conversely, if a sweetened yoghurt had a current sugar content of 15 $\mathrm{g} / 100 \mathrm{~g}$, then we assumed it would be reformulated to $12.5 \mathrm{~g} / 100 \mathrm{~g}$. For food and beverage categories with a proportional reduction target, a $10 \%$ reduction in the sugar content was applied to products that exceeded the category-specific threshold. For example, in the carbonated soft drinks and energy drinks where a 10\% reduction target applies to products containing more than $10 \mathrm{~g}$ of sugar per $100 \mathrm{~mL}$, if a product had a sugar content of 9 $\mathrm{g} / 100 \mathrm{~mL}$ then we assumed the sugar content would not change. However, if a product had a sugar content of 12 $\mathrm{g} / 100 \mathrm{~mL}$ then we assumed it would be reformulated to $10.8 \mathrm{~g} / 100 \mathrm{~mL}$. As it is unclear whether product reformulation can lead to changes in dietary behaviour, we assumed that purchasing habits would not be affected by reformulation (i.e. baseline purchases would remain the same post reformulation). 


\section{UK government sugar reduction targets}

We also modelled the potential impact of the UK sugar reduction program on household sugar purchases [12]. This program aims to reduce the total sugar content of targeted products by $20 \%$ through three key strategies: reformulation to lower the sugar content of products, portion size guidelines to reduce the portion size of single serve foods, and shifting consumer purchasing towards lower/no added sugar products (Supplementary Table 2). To model potential reductions, we applied a $20 \%$ reduction in the 2018 sugar content of all targeted foods and beverages. For example, if a yoghurt had a sugar content of $10 \mathrm{~g} / 100 \mathrm{~g}$, then we assumed the sugar content would be reduced to $8 \mathrm{~g} / 100 \mathrm{~g}$. This was applied across each relevant product purchased by Australian households in 2018 to ensure reductions were weighted according to sales. Following the UK guidelines, a small allowance for naturally occurring sugars (lactose) for products in the yoghurt category was made by removing $3.8 \mathrm{~g}$ of sugar per $100 \mathrm{~g}$ from the total sugar content before applying the $20 \%$ reduction.

\section{Statistical analysis}

We first calculated the number of unique products targeted by the Australian and UK sugar reduction programs, as well as the proportion (\%) of these products purchased by Australian households in 2018 that already met the Australian and UK targets. We then calculated current sugar purchases per capita from targeted food categories i.e. the amount of sugar in grams (as indicated on pack) purchased daily per person, by dividing total household sugar purchases per year, by 365 days, and by the number of individuals within the household. We then calculated sugar purchases per capita with the sugar reduction targets applied to assess how much sugar Australians would purchase after full adoption of the Australian and UK sugar reduction programs. We used the difference in sugar purchases before and after application of the sugar targets to calculate the change in mean sugar purchases per capita.

We also explored changes to mean sugar purchases per capita across household income level. The Organisation for Economic Co-operation and Development (OECD)modified equivalized scales were applied to calculate gross equivalized household income [33, 34]. Three income groups were generated with an approximately equal number of households in each group: low-income households (<AUD\$28,750 per year); middle-income households (AUD\$28,750 - \$55,000 per year) and highincome households (>AUD $\$ 55,000$ per year). Reductions in per capita sugar purchases were compared across groups using 1-factor ANOVA with post-hoc pairwise tests.
To ensure the NielsenIQ Homescan panel is representative of socio-economic, demographic and geographic composition of the Australian population, NielsenIQ uses census data [35] to generate sample weights to allow findings based on the panel to be projected up to the Australian population in 2018. All of the results presented in this paper use the sample weights provided by NielsenIQ and are representative of the Australian population [35]. All statistical analyses were performed using Stata V.16.0 (StataCorp). A two-sided p-value of $<0.05$ was considered statistically significant.

To explore the potential influence of under-reporting, a sensitivity analysis was conducted whereby households whose annual food and beverage expenditure were $\leq 5$ th percentile were excluded, with the percentile value defined separately for single and multi-member households.

\section{Results}

\section{Characteristics of the NielsenIQ Homescan Panel}

In 2018, the Homescan panel included 11,056 households. Of these, 3,868 were excluded for not meeting eligibility criteria, leaving 7,188 households for the current analysis (Supplementary Figure 1). The main household shopper tended to be female $(68.4 \%)$ and over the age of $40(88.4 \%)$. Most households consisted of one or two persons $(56.8 \%)$, which is consistent with Australian census data from 2016 (58\%) [35]. In terms of household composition, the most common was families with children aged 11-17 years old (41.4\%), followed by older singles and couples over the age of $45(23.6 \%)$. The mean equivalized annual household income across all households was $\$ 46,987$ AUD. The education level of the main household shopper was mainly high school/trade/diploma (41.5\%), followed by bachelor's degree or higher (22.3\%), and less than high school (20.5\%). A description of household characteristics is provided in Supplementary Table 3.

\section{Overall impact of the Australian reformulation program on per capita sugar purchases}

Across the 25,261 unique products that matched across the Nielsen and FoodSwitch databases, only 9.8\% were in product categories eligible for a sugar reformulation target $(\mathrm{n}=2,471)$, which represented $9.5 \%$ of all products purchased by Australian households in 2018. Just over half $(52.4 \%)$ of these targeted products already met the sugar targets. In terms of beverage categories, this ranged from as low as $26.3 \%$ for fruit drinks up to $83.3 \%$ for flavoured waters. For the food categories, this ranged from $49.6 \%$ for muesli and snack bars to $69.8 \%$ for sweetened yoghurt (Table 1).

In 2018, the total sugar (mean \pm SE) purchased from these targeted food categories at baseline was $10.2 \pm 0.0 \mathrm{~g} /$ 
Table 1 Modelled impact of the Australian sugar reformulation targets on Australian household purchases of sugar

\begin{tabular}{|c|c|c|c|c|c|c|}
\hline \multirow[t]{2}{*}{ Food category ${ }^{a}$} & \multirow[t]{2}{*}{ Sub-category } & \multirow{2}{*}{$\begin{array}{l}\text { Number of unique } \\
\text { products subject to } \\
\text { reformulation }\end{array}$} & \multirow{2}{*}{$\begin{array}{l}\text { Products already } \\
\text { meeting target } \\
\text { (\%) }\end{array}$} & \multicolumn{3}{|c|}{ Mean sugar purchases (g/d per capita) } \\
\hline & & & & Current & $\begin{array}{l}\text { Reformulated } \\
\text { to meet } \\
\text { targets }^{\mathrm{d}}\end{array}$ & $\begin{array}{l}\text { Difference } \\
\text { (Current - targets } \\
\text { applied) }\end{array}$ \\
\hline All categories combined & & 2471 & 52.4 & 10.22 & 9.36 & 0.87 \\
\hline \multirow[t]{2}{*}{ Breakfast Cereals } & $\begin{array}{l}\text { Breakfast cereals with } \\
\text { fruit }\end{array}$ & 226 & 65.0 & 0.85 & 0.79 & 0.06 \\
\hline & $\begin{array}{l}\text { Breakfast cereals without } \\
\text { fruit }\end{array}$ & 222 & 58.9 & 0.94 & 0.83 & 0.11 \\
\hline \multirow[t]{2}{*}{ Flavoured milk } & $\begin{array}{l}\text { Flavoured milk: Mam- } \\
\text { malian }\end{array}$ & 177 & 42.5 & 0.71 & 0.65 & 0.05 \\
\hline & $\begin{array}{l}\text { Flavoured milk: Dairy } \\
\text { alternatives }\end{array}$ & 29 & 59.4 & 0.02 & 0.02 & 0.00 \\
\hline Muesli and snack bars & Muesli and snack bars & 310 & 49.6 & 0.45 & 0.41 & 0.03 \\
\hline \multirow[t]{3}{*}{ Non-alcoholic beverages } & $\begin{array}{l}\text { Flavoured water, mineral } \\
\text { water, soda water and } \\
\text { iced tea }\end{array}$ & 326 & 83.3 & 0.22 & 0.20 & 0.01 \\
\hline & $\begin{array}{l}\text { Carbonated soft drinks } \\
\text { and energy drinks }\end{array}$ & 576 & 29.5 & 5.12 & 4.69 & 0.44 \\
\hline & Fruit drinks & 130 & 26.3 & 0.81 & 0.74 & 0.07 \\
\hline Sweetened yoghurt & $\begin{array}{l}\text { Sweetened yoghurt: } \\
\text { Mammalian }\end{array}$ & 475 & 69.8 & 1.10 & 1.01 & 0.09 \\
\hline
\end{tabular}

${ }^{\text {a }}$ Food categories and sub-categories listed are those that are targeted by the Australian government's sugar reformulation program

${ }^{b}$ Results are sales-weighted and are projected to the Australian population using sample weights provided by NielsenIQ

' Standard error (SE) for mean sugar purchases ( $\mathrm{g} / \mathrm{d}$ per capita) not displayed as SE $\leq 0.01$ for each mean value

${ }^{d}$ For food categories with a maximal target, foods and beverages with a sugar content at or below the target-level retained their existing sugar content, whereas, foods and beverages. For food categories with a proportional reduction target, a $10 \%$ sugar reduction was applied to products that met the criteria

day per capita, representing $18.2 \%$ of all sugar purchased from packaged foods and beverages in 2018 (56.1 \pm 0.0 $\mathrm{g} /$ day per capita). This was predominately attributed to purchases of carbonated soft drinks and energy drinks $(5.1 \mathrm{~g} / \mathrm{d}$ per capita, $50.1 \%$ of all sugar purchased across targeted food categories), sweetened yoghurt $(1.1 \mathrm{~g} / \mathrm{d}$ per capita, $10.8 \%)$ and breakfast cereals without fruit $(0.9 \mathrm{~g} / \mathrm{d}$ per capita, 9.2\%) (Table 1). It was estimated that if food companies were to reformulate all existing products to meet Australia's sugar targets, this would reduce baseline mean sugar purchases by $0.9 \mathrm{~g} /$ day per capita, representing an $8.5 \%$ reduction in sugar across targeted food categories and a $1.5 \%$ reduction in sugar purchased from all packaged foods and beverages. Across the nine food categories targeted, the mean reductions were projected to be largest for carbonated soft drinks and energy drinks (0.4 $\mathrm{g} / \mathrm{d}$ per capita, $50.3 \%$ of all projected reductions), breakfast cereals without fruit $(0.1 \mathrm{~g} / \mathrm{d}$ per capita, $13.1 \%)$ and sweetened yoghurt $(0.1 \mathrm{~g} / \mathrm{d}$ per capita, $10.1 \%)$ (Table 1$)$.

Across the targeted food categories, per capita sugar purchases were marginally higher for low-income households compared to high-income households $(2.5 \mathrm{~g} /$ day, 95\%CI: $1.6-3.5 \mathrm{~g} /$ day, $P<0.001$ ) (Table 2). If all food companies met the targets in full, this would result in a marginally greater absolute reduction in per capita sugar
Table 2 Modelled impact of the Australian sugar reformulation targets on changes to sugar purchases ( $\mathrm{g} / \mathrm{d}$ per capita), by income level

\begin{tabular}{llll}
\hline & \multicolumn{2}{l}{$\begin{array}{l}\text { Mean sugar purchases across targeted food } \\
\text { categories (g/d per capita) } \text { Inc }^{\mathbf{b}, \mathbf{c}}\end{array}$} \\
\cline { 2 - 4 } Income level $^{\mathrm{a}}$ & Current & $\begin{array}{l}\text { Reformulated to } \\
\text { meet targets }^{\mathrm{d}}\end{array}$ & $\begin{array}{l}\text { Mean difference } \\
\text { (current - targets } \\
\text { applied) }\end{array}$ \\
\hline Low & 11.64 & 10.63 & 1.01 \\
Middle & 10.30 & 9.42 & 0.88 \\
High & 9.17 & 8.41 & 0.75
\end{tabular}

${ }^{a}$ The OECD-modified equivalence scale was applied to calculate equivalised household income (adjusting for household size and age of household members). Three income groups (low, middle and high) were then generated by splitting households into three groups of approximately equal numbers. The three household income groups (low: $<\$ 28,750$ per year, middle: $\$ 28,750$ - $\$ 55,000$ per year and high: $>\$ 55,000$ per year) had mean incomes that were comparable to equivalised incomes for the Australian population in 2016 (low income: $\leq 30$ th percentile $\leq \$ 33,020$; middle-income: $30-60$ th percentile: $\$ 33,021-51,324$, high-income: $>60$ th percentile $\geq \$ 51,325$ )

${ }^{b}$ SE for sugar purchases ( $g /$ day per capita) not displayed as $S E \leq 0.01$ for each mean value

' Results are sales weighted and are projected to the Australian population using sample weights provided by NielsenIQ

${ }^{d}$ Foods with per $100 \mathrm{~g}$ sugar values at or below the target retained their sugar content, whereas foods with per $100 \mathrm{~g}$ sugar values above the target had the sugar content replaced with the sugar target 
purchases for low-income households compared with high-income households (mean difference $0.3 \mathrm{~g} /$ day, $95 \%$ CI $0.2-0.4 \mathrm{~g} /$ day, $P<0.001)$.

\section{Potential impact if Australia adopted the UK sugar reduction targets}

The UK sugar reduction targets cover approximately twice as many products as the Australian targets (4,667 versus 2,471 unique foods and beverages). The total sugar (mean $\pm \mathrm{SE}$ ) acquired from the UK targeted food categories at baseline was $20.9 \pm 0.0 \mathrm{~g} /$ day per capita, representing $37.3 \%$ of all sugar purchased from packaged foods and beverages in 2018 . This was predominately attributed to purchases of ice cream, lollies and sorbets $(4.8 \mathrm{~g} / \mathrm{d}$ per capita, $22.7 \%$ of all sugar purchased across targeted food categories), chocolate confectionery (4.4 g/d per capita, 20.9\%) and biscuits/cookies (2.9 g/d per capita, 13.7\%) (Table 3).

It was estimated that if all food and beverage companies were to reformulate their products to meet the UK sugar reduction targets, the impact on sugar purchases would be more than four-times greater compared with the current Australian targets, resulting in a mean reduction of $4.1 \mathrm{~g} /$ day per capita (Table 3 ). This is equivalent to a $7.3 \%$ reduction in total sugar from all packaged food and beverage purchases at baseline. A large proportion of the per capita reduction from the UK targets came from food categories not covered by the Australian targets including ice cream, lollies and sorbets $(1.0 \mathrm{~g} /$ day $)$, chocolate confectionery ( $0.9 \mathrm{~g} /$ day $)$ and biscuits/cookies (0.6 g/day) (Table 3).
It was estimated that low-income households had significantly higher per capita sugar purchases from the food categories targeted by the UK targets compared to highincome households (by 5.8g/day, 95\%CI: 4.7 - 7.0g/day, $\mathrm{P}<0.001$ ) (Supplementary Table 4). If all food companies met the targets in full, this would result in a marginally greater absolute reduction in per capita sugar purchases for low-income households compared with high-income households (mean difference $1.1 \mathrm{~g} /$ day, $95 \%$ CI 0.9 - $1.4 \mathrm{~g} /$ day, $P<0.001)$.

\section{Sensitivity analysis}

Excluding households in the lowest 5 th percentile for total annual spend for foods and beverages did not appreciably change sugar reduction estimates for either the Australian or UK target scenarios at $0.9 \mathrm{~g} / \mathrm{d}$ per capita and $4.2 \mathrm{~g} / \mathrm{d}$ per capita, respectively.

\section{Discussion}

Our analyses indicate that Australia's voluntary sugar reformulation targets will likely have only a small impact on reducing sugar consumption across the Australian population. This is a concern considering excess sugar intakes can increase energy intakes and reduce overall diet quality, which may lead to weigh gain and increased risk of non-communicable disease $[1,5,6]$. With almost half of the Australian population consuming free sugar in excess, the ongoing absence of credible mechanisms to address high sugar levels in packaged foods and beverages is a cause for concern.

Table 3 Modelled impact of the UK sugar reduction targets on Australian household purchases of sugar

\begin{tabular}{|c|c|c|c|c|}
\hline \multirow[t]{2}{*}{ Food category ${ }^{a}$} & \multirow{2}{*}{$\begin{array}{l}\text { Number of unique products subject } \\
\text { to sugar reduction }\end{array}$} & \multicolumn{3}{|c|}{ Mean sugar purchases (g/d per capita) $)^{b, c}$} \\
\hline & & Current & $\begin{array}{l}\text { Sugar levels reduced } \\
\text { by } 20 \%\end{array}$ & $\begin{array}{l}\text { Difference } \\
\text { (Current - targets } \\
\text { applied) }\end{array}$ \\
\hline Overall & 4667 & 20.94 & 16.87 & 4.07 \\
\hline Breakfast cereals & 524 & 1.89 & 1.51 & 0.38 \\
\hline Biscuits/cookies & 607 & 2.87 & 2.29 & 0.57 \\
\hline Cakes & 283 & 0.87 & 0.70 & 0.17 \\
\hline Chocolate confectionery & 890 & 4.37 & 3.49 & 0.87 \\
\hline Ice cream, lollies and sorbets & 560 & 4.76 & 3.81 & 0.95 \\
\hline Morning goods & 106 & 0.35 & 0.28 & 0.07 \\
\hline Puddings & 460 & 1.23 & 0.99 & 0.25 \\
\hline Sweet confectionery & 483 & 2.11 & 1.69 & 0.42 \\
\hline Yoghurts & 456 & 1.09 & 0.94 & 0.15 \\
\hline Sweet spreads and sauces & 298 & 1.38 & 1.14 & 0.23 \\
\hline
\end{tabular}

${ }^{a}$ Food categories and sub-categories listed are those that are targeted by the UK government's sugar reduction program

${ }^{\mathrm{b}}$ Results are sales-weighted and are projected to the Australian population using sample weights provided by NielsenIQ

c Standard error (SE) for mean sugar purchases ( $\mathrm{g} / \mathrm{d}$ per capita) not displayed as SE $\leq 0.01$ for each mean value 
Our analyses suggest two critical weaknesses of the current Australian sugar reduction program. First, the target levels for sugar reduction are too lenient, with more than a half of the products covered by the program already meeting the reformulation targets prior to implementation. This conflicts directly with the stated aim of the reformulation program specified by government at the outset, which indicated that the targets would be set at a level whereby only one-third of products would already be at or below target [15]. The second issue is that the coverage of the program is too narrow; missing high sugar food categories including ice cream, lollies and sorbets, chocolate confectionery and biscuits/cookies $[8,20$, 36]. The government could resolve these issues by setting lower sugar target levels to ensure only one-third of products meet the targets at baseline (thereby requiring a greater proportion of products to be reformulated), targeting a broader range of sugary food categories, and by introducing a wider range of sugar reduction policies to complement reformulation. The impact of these omissions is objectively demonstrated by comparison against the UK program, which if applied in Australia would cover twice as many products and deliver more than four times the sugar reduction. The addition of portion size guidelines to Australia's sugar reduction program, whereby hard-to-reformulate products can be provided in smaller size packs, may provide opportunities to generate further impact on population sugar consumption.

Several technical issues are likely to have hampered the Australian government in designing the current sugar reformulation program. Firstly, the targets were set using information about the sugar content in products from a nutrition composition database with limited market coverage (a total of $\sim 40,000$ products since it started in 2014) [37] compared with $>20,000$ products collected each year from FoodSwitch (the database used in this analysis) [38]. The government also elected not to use purchase data during the target setting process and therefore were unable to account for the different quantities of products purchased by Australian households [15]. Use of purchase data would have added a further level of rigour to the target setting process, particularly in food categories where the sugar content of market-leading products differs substantially from the category average. The government was aware of the limited impact of these targets as they commissioned modelling work during the target setting process to estimate the likely impact of the reformulation targets on population diets [15]. Similar to our estimates in this study, this modelling work estimated the under that scenario that all food companies complied with the targets, sugar intakes would be reduced by just $1.3 \mathrm{~g} / \mathrm{d}$ capita [15]. The small estimated reductions highlight the need for the government to introduce a more multi-sectoral approach for setting nutrition policies in Australia. While this could involve some engagement with the food industry regarding potential policies, representatives from the food industry should not be involved in setting nutrition policies in accordance with best practice as recommended by the WHO [39].

There was ample opportunity for the government to revise the targets during the target setting stage to leverage the extensive work undertaken by the UK government [40]. In addition to delivering targets that could have achieved significant reductions in sugar intake, if Australia had adopted the UK program in Australia, this would also have saved considerable time since the UK targets have been available since 2017; a full four years before the release of the Australian targets [17]. Adapting the UK targets to the Australian context should be feasible given these countries have comparable food supplies in terms of types of food available for sale and their nutritional quality [40]. However, as the UK sugar reduction program is much more comprehensive, adopting these targets in Australia would require political will and it may be difficult to generate such strong support from policymakers.

While already small in magnitude, our estimate of the impact of the Australian sugar reduction program is certainly optimistic. Given this is a voluntary program with no sanction for companies that fail to meet the targets, it is very unlikely that the food industry will fully comply, particularly given the previous reformulation targets in Australia showed varying levels of uptake across food companies with some achieving full reformulation across their products and others achieving very little [41-43]. Strong political engagement, media pressure and regular monitoring of progress are key to the successful implementation of voluntary policies such as Australia's sugar targets $[43,44]$. There is, however, no evidence that these accountability measures will be used by the Australian government to help deliver upon these very modest targets [43].

Our modelling estimated the effects of the Australian sugar reduction targets on total sugar purchases from packaged foods but the estimated effect on free sugars is similarly inconsequential. Australian adults consume on average $60 \mathrm{~g}$ of free sugar per day [15], the current reformulation program would reduce daily free sugar intake by only about $1.5 \%$. Even full adoption of the UK targets in Australia would fail to reduce average Australian free sugar intake (currently about $17 \%$ of daily energy intake) to a level close to the WHO recommended maximum of $10 \%$ of daily energy intake [6]. To achieve needed reductions in population free sugar consumption, our findings suggest that multiple policies rather than just reformulation may be needed, particularly as reformulation can 
face technological limitations in regard to food safety and consumer acceptability of taste, appearance and texture [45] and may not be the most feasible approach for all foods and beverages. Previous research has identified five action areas for reducing population intakes of free sugar in Australia [44]. These include prioritising health in policy and trade agreements; introducing fiscal policies to support health and promote reformulation; improving food labelling and advertising regulations; strengthening Australian dietary guidelines and introducing measures to encourage healthier choices, such as increasing healthy food and beverage offerings at hospitals, universities and workplaces [44].

Our findings are consistent with prior studies indicating that individuals from more deprived socio-economic backgrounds are more likely to consume diets higher in sugar $[8,18-20]$. Despite the relatively weak sugar reformulation policy in Australia, our analysis has demonstrated that the targets could lead to small, albeit statistically significant, differences in absolute sugar reduction between high and low income households, thereby demonstrating the potential for upstream policies, such as reformulation, to reduce socioeconomic inequalities in sugar intakes. This is evident through our finding that the UK sugar reduction targets, which are more comprehensive and stringent compared to Australia's targets, holds greater promise to deliver more meaningful sugar reductions for low socio-economic households. While we have quantified the potential absolute differences in sugar reduction across households of different income levels, future studies should assess how Australia's reformulation program could translate into other outcomes impacted by socio-economic status, such as non-communicable disease risk. Given the need to reduce socio-economic disparities in diet across the Australian population, future modelling studies should look to assess a range of different reformulation scenarios to determine which strategies are likely to have the greatest impact on reducing sugar intakes across the lowest socio-economic groups. Such research will be critical for informing future reformulation policies in Australia.

A major strength of this study was our use of contemporary purchase data from a representative sample of Australian households [46]. Moreover, we were able to match this data to an up-to-date packaged food database containing product-specific sugar content information collected from grocery retailers, which together represent about $80 \%$ of total market share in Australia [29]. Purchase data and sugar content levels were directly linked for each individual product using unique barcode and product name information. This not only minimised the risk of errors related to the sugar content, it also ensured our results accurately reflected both the purchasing habits of Australian households and the nutritional composition of the food supply. This information allowed us to forecast the potential impact of the Australian reformulation program on sugar purchases with significant confidence, overall, for individual food categories. Moreover, our comparison to the UK sugar reduction program meant we were able to provide a realworld recommendation about how the Australian program could be strengthened immediately in a realistic and feasible way.

Limitations to the analyses are that households report the amount of purchased foods and beverages, not the amounts consumed, and wastage is therefore not incorporated into the estimates. It is also likely that there is under-reporting of purchases which has been previously estimated to be about 10-20\% for NielsenIQ Homescan data, a level that is similar to several dietary intake assessment methods [47, 48]. Moreover, NielsenIQ Homescan only collects information about food and beverages brought into the home. As we were unable to estimate the amount of sugar reduction from purchases of foods and beverages consumed outside of home such as from restaurants and cafes, it is likely we have slightly underestimated the impact of sugar reformulation targets on total sugar purchases. While the majority of main household shoppers in NielsenIQ Homescan were above 40 years of age, this is not representative of the entire sample given the main household shopper is likely to be an adult and/or parent who purchases groceries on behalf of the household. It is also likely that some selection bias is present in the NielsenIQ data given participation in the panel relies on households to volunteer. However, the use of sample weights reduced the likelihood of such sampling biases impacting the representativeness of the results. Lastly, we acknowledge that achieving maximal reductions with Australia's sugar targets and the UK sugar reduction program is optimistic and that in reality, voluntary compliance means actual impact on population sugar intake is likely to be even lower than our estimates. Future research is needed to explore where the Australian sugar targets should be set to ensure only one-third of products meet the targets at baseline and what impact this would have on reducing sugar consumption across the population.

\section{Conclusion}

Sugar-reduction policies, including reformulation, have significant potential to reduce population sugar intake but only if they are well designed and implemented. With a large disease burden attributable to excess sugar consumption in Australia, these data indicate an urgent need for the Australian government to review and enhance its approach to this important health challenge. Our 
findings suggest that the current Australian government reformulation targets will have a negligible impact on sugar consumption in Australia, because the targets set are insufficiently ambitious, and the breadth of products covered is limited.

\section{Abbreviations}

WHO: World health organization; NIP: Nutritional information panel; OECD: Organisation for Economic Co-operation and Development.

\section{Supplementary Information}

The online version contains supplementary material available at https://doi. org/10.1186/s12966-021-01208-6.

Additional file 1: Supplementary Table 1. List of the Australian sugar reformulation targets [1]. Supplementary Table 2 . List of the food categories included in the UK sugar reduction targets [2]. Supplementary Figure 1. Participant flow diagram. Supplementary Table 3. Household characteristics of the NielsenlQ Homescan Consumer panel in 2018. Supplementary Table 4. Modelled impact of the UK sugar reduction targets on changes to sugar purchases ( $\mathrm{g} / \mathrm{d}$ per capita), by income level

\section{Acknowledgements}

We thank Luke Starick and Phil Turnbull from NielsenIQ for their assistance and provision of Homescan data.

\section{Authors' contributions}

DHC and JHYW designed the research; DHC and MS conducted the research and analysed data; $\mathrm{DHC}$ wrote the paper; $\mathrm{DHC}$ had primary responsibility for final content. All authors provided critical feedback on the manuscript and read and approved the final manuscript

\section{Funding}

This research received no external funding. DHC is supported by an Australian Government Research Training Program (RTP) Scholarship and George Institute Top-Up Scholarship. KT was supported by an Early Career Fellowship (APP1 161597) from the National Health and Medical Research Council of Australia (NHMRC) and a Postdoctoral Fellowship (Award ID 102140) from the National Heart Foundation of Australia. This work was supported by an NHMRC Partnership Project (APP1167745) and an NHMRC Centres of Research Excellence (CRE) grant (APP1117300). The funding bodies were not involved in the study design, data collection, analysis, interpretation or drafting of the manuscript. Open Access funding was enabled by an NHMRC Centres of Research Excellence (CRE) grant (APP1117300).

\section{Availability of data and materials}

The data that support the findings of this study are available from Nielse$\mathrm{nIQ}$ and FoodSwitch, but restrictions apply to the availability of these data, which were used under license for the current study, and so are not publicly available.

\section{Declarations}

Ethics approval and consent to participate

This project was approved by the University of New South Wales Human Research Ethics Committee (approval number HC180965). All participants originally gave informed consent to participate in the Nielsen Homescan Panel including consent for their data to be used for future research purposes.

\section{Consent for publication}

Not applicable.

\section{Competing interests}

The authors declare that they have no competing interests.

\section{Author details}

${ }^{1}$ Faculty of Medicine, The George Institute for Global Health, UNSW Sydney, Level 5, 1 King St, Newtown, Australia. ${ }^{2}$ Department of Nutrition, The University of North Carolina at Chapel Hill, Chapel Hill, USA. ${ }^{3}$ School of Biological Sciences, Faculty of Science, The University of Hong Kong, Pokfulam, Hong Kong, SAR, China. ${ }^{4}$ Department of Epidemiology, Johns Hopkins Bloomberg School of Public Health, Baltimore, MD, USA.

Received: 20 June 2021 Accepted: 5 October 2021

Published online: 28 October 2021

\section{References}

1. MalikV, Pan A, Willett W, et al. Sugar-sweetened beverages and weight gain in children and adults: a systematic review and meta-analysis. Am J Clin Nutr. 2013;98:1084-102.

2. Te Morenga L, Mallard S, Mann J. Dietary sugars and body weight: systematic review and meta-analyses of randomised controlled trials and cohort studies. BMJ. 2012;346:e7492

3. Moynihan PJ, Kelly SA. Effect on caries of restricting sugars intake: systematic review to inform WHO guidelines. J Dent Res. 2014;93:8-18.

4. de Koning L, Malik V, Rimm E, et al. Sugar-sweetened and artificially sweetened beverage consumption and risk of type 2 diabetes in men. Am J Clin Nutr. 2011;93:1321-7.

5. Malik VS, Popkin BM, Bray GA, et al. Sugar-sweetened beverages and risk of metabolic syndrome and type 2 diabetes: a meta-analysis. Diabetes Care. 2010;33:2477-83.

6. World Health Organization. Guideline: Sugar intake for adults and children, WHO Department of Nutrition for Health and Development (NHD), Editor. 2015, WHO: Geneva. p. 50.

7. Gupta A, Smithers L, Braunack-Mayer A, et al. How much free sugar do Australians consume? Findings from a national survey. Aust N Z J Public Health. 2018;42:533-40.

8. Lei L, Rangan A, Flood V, et al. Dietary intake and food sources of added sugar in the Australian population. Br J Nutr. 2016;115:868-77.

9. Martínez Steele E, Baraldi L, Louzada M, et al. Ultra-processed foods and added sugars in the US diet: evidence from a nationally representative cross-sectional study. BMJ Open. 2016;6:1-8.

10. Neri D, Martinez-Steele E, Monteiro C, et al. Consumption of ultra-processed foods and its association with added sugar content in the diets of US children, NHANES 2009-2014. Pediatr Obes. 2019;14:1-11.

11. Tamir O, Cohen-Yogev T, Furman-Assaf S, et al. Taxation of sugar sweetened beverages and unhealthy foods: a qualitative study of key opinion leaders' views. Israel J Health Pol Res. 2018;7:1-11.

12. Public Health England. Sugar Reduction: achieving the $20 \%$. Available online: https://assets.publishing.service.gov.uk/government/uploads/ system/uploads/attachment_data/file/604336/Sugar_reduction_achie ving_the_20_.pdf. Accessed 21 Jun 2021.

13. Amies-Cull B, Briggs A, Scarborough P. Estimating the potential impact of the UK government's sugar reduction programme on child and adult health: modelling study. BMJ. 2019;365:1-8.

14. Australian Bureau of Statistics. 4364.0.55.011 - Australian Health Survey: consumption of added sugars, 2011-12 Available online: https://www. abs.gov.au/ausstats/abs@.nsf/Lookup/4364.0.55.011main+features10 2011-12. Accessed 17 Mar 2021.

15. The Department of Health, Healthy food partnership reformulation program: evidence informing the approach, draft targets and modelling outcomes, The Department of Health, Editor. 2018, Australian Government: Canberra, ACT.

16. Department of Health. About the healthy food partnership. Available online: https://www.health.gov.au/initiatives-and-programs/healthyfood-partnership/about-the-healthy-food-partnership. Accessed 3 Sept 2021.

17. Department of Health. Partnership reformulation program - summary of food categories and reformulation targets. Available online: https://www. health.gov.au/resources/publications/partnership-reformulation-progr am-summary-of-food-categories-and-reformulation-targets. Accessed 3 Sept 2021.

18. Thompson F, McNeel T, Dowling E, et al. Interrelationships of added sugars intake, socioeconomic status, and race/ethnicity in adults in the 
United States: National Health Interview Survey, 2005. J Am Diet Assoc. 2009;109:1376-83.

19. Park S, Thompson F, McGuire L, et al. Sociodemographic and behavioral factors associated with added sugars intake among US adults. J Acad Nutr Diet. 2016;116:1589-98.

20. Coyle D, Shahid M, Dunford E, et al. The contribution of major food categories and companies to household purchases of added sugar in Australia. J Acad Nutr Diet. 2021.

21. Nielsen Consumer LLC. NielsenIQ. Available online: https://nielseniq.com/ global/en/solutions/homescan/. Accessed 26 Aug 2021.

22. Coyle D, Shahid M, Dunford E, et al. Contribution of major food companies and their products to household dietary sodium purchases in Australia. Int J Behav Nutr Phys Act. 2020;17:1-9.

23. Poti J, Dunford E, Popkin B. Sodium reduction in US households' packaged food and beverage purchases, 2000 to 2014. JAMA Intern Med. 2017:177:986-94.

24. Grummon A, Taillie L. Supplemental nutrition assistance program participation and racial/ethnic disparities in food and beverage purchase. Public Health Nutr. 2018;21:3377-85.

25. Poti J, Mendez M, Ng S, et al. Is the degree of food processing and convenience linked with the nutritional quality of foods purchased by US households? Am J Clin Nutr. 2015;101:1251-62.

26. Dunford E, Trevena H, Goodsell C, et al. FoodSwitch: a mobile phone app to enable consumers to make healthier food choices and crowdsourcing of national food composition data. JMIR Mhealth Uhealth. 2014;2:1-11.

27. Coyle D, Ndanuko R, Singh $S$, et al. Variations in sugar content of flavored milks and yogurts: a cross-sectional study across 3 countries. Curr Dev Nutr. 2019;3:1-7.

28. Crino M, Sacks G, Dunford E, et al. Measuring the healthiness of the packaged food supply in Australia. Nutrients. 2018;10:1-17.

29. Morgan R. Looking beyond the panic-buying, Australia's big supermarket story is Aldi's growing market share. Available online: http://www.roymo rgan.com/findings/8336-fresh-food-and-grocery-report-december-2019202003230634. Accessed on 29 Sept 2021.

30. Dunford E, Webster J, Metzler AB, et al. International collaborative project to compare and monitor the nutritional composition of processed foods. Eur J Prev Cardiol. 2012;19:1326-32.

31. Coyle D, Shahid M, Dunford E, et al. Estimating the potential impact of Australia's reformulation programme on households' sodium purchases. BMJ Nutr Prev Health. 2021;4:49-58.

32. Slining MM, Ng SW, BM., P. Food companies' calorie-reduction pledges to improve U.S. diet. Am J Prev Med. 2013;44:174-84.

33. Organisation for Economic Co-operation and Development. What are equivalence scales? Available online: http://www.oecd.org/els/soc/ OECD-Note-EquivalenceScales.pdf. Accessed 21 Jun 2021.

34. Australian Bureau of Statistics. Equivalised total household income. Available online: https://www.abs.gov.au/websitedbs/censushome.nsf/home/ statementsdwellinghied?opendocument\&navpos=430. Accessed $21 \mathrm{Jun}$ 2021.
35. Australian Bureau of Statistics. 2016 Census. Available online: https:// www.abs.gov.au/websitedbs/censushome.nsf/home/2016. Accessed 21 Jun 2021.

36. Australian Bureau of Statistics. Australian health survey: nutrition first results - foods and nutrients. Available online: https://www.abs.gov.au/ statistics/health/health-conditions-and-risks/australian-health-surveynutrition-first-results-foods-and-nutrients/latest-release. Accessed 27 May 2021

37. CSIRO, FoodTrack ${ }^{\mathrm{TM}}$ food \& nutrient database.

38. Rosewarne E, Huang L, Farrand C, et al. Assessing the healthy food partnership's proposed nutrient reformulation targets for foods and beverages in Australia. Nutrients. 2020;12:1-12.

39. World Health Organization. Addressing and managing conflicts of interest in the planning and delivery of nutrition programmes at country level. Geneva:WHO; 2015.

40. Dunford E, Ni Mhurchu C, Huang L, et al. A comparison of the healthiness of packaged foods and beverages from 12 countries using the Health Star Rating nutrient profiling system, 2013-2018. Obes Rev. 2019;20:107-15.

41. Sacks G, Mialon M, Vandevijvere S, et al. Comparison of food industry policies and commitments on marketing to children and product (re)formulation in Australia, New Zealand and Fiji. Crit Public Health. 2014;25:299-319.

42. Trevena $\mathrm{H}, \mathrm{Neal} B$, Dunford $\mathrm{E}$, et al. An evaluation of the effects of the Australian Food and Health Dialogue targets on the sodium content of bread, breakfast cereals and processed meats. Nutrients. 2014;6:3802-17.

43. Jones A, Magnusson R, Swinburn B, et al. Designing a Healthy Food Partnership: lessons from the Australian Food and Health Dialogue. BMC Public Health. 2016;16:1-10.

44. Gupta A, Miller C, Harford J, et al. Australia's sugar tale. Public Health Nutr. 2019:22:2682-7.

45. Markey O, Lovegrove J, Methven L. Sensory profiles and consumer acceptability of a range of sugar-reduced products on the UK market. Food Res Int. 2015;72:133-9.

46. World Health Organization. Using third-party food sales and composition databases to monitor nutrition policies. Available online: https://apps. who.int/iris/handle/10665/339075. Accessed 21 Jul 2021.

47. Zhen C, Taylor J, Muth M, et al. Understanding differences in self-reported expenditures between household scanner data and diary survey data: a comparison of Homescan and consumer expenditure survey. Rev Agric Econ. 2009;31:470-92

48. Einav L, Leibtag E, Nevo A. Recording discrepancies in Nielsen Homescan data: are they present and do they matter? Quant Mark Econ. 2010:8:207-39

\section{Publisher's Note}

Springer Nature remains neutral with regard to jurisdictional claims in published maps and institutional affiliations.
Ready to submit your research? Choose BMC and benefit from:

- fast, convenient online submission

- thorough peer review by experienced researchers in your field

- rapid publication on acceptance

- support for research data, including large and complex data types

- gold Open Access which fosters wider collaboration and increased citations

- maximum visibility for your research: over 100M website views per year

At BMC, research is always in progress.

Learn more biomedcentral.com/submissions 